\title{
Giant left main coronary artery aneurysm: How to deal with it?
}

Giovanni A. Chiariello, MD, ${ }^{\mathrm{a}}$ Piergiorgio Bruno, MD, ${ }^{\mathrm{a}}$ Federico Cammertoni, MD, ${ }^{\mathrm{a}}$ Natalia Pavone, MD, ${ }^{\mathrm{a}}$ Andrea Mazza, MD, ${ }^{\mathrm{a}}$ Biagio Merlino, MD, ${ }^{\mathrm{b}}$ and Massimo Massetti, MD, ${ }^{\mathrm{c}}$ Rome, Italy

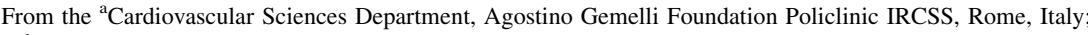
${ }^{b}$ Radiology Department, Agostino Gemelli Foundation Policlinic IRCSS, Catholic University of The Sacred Heart, Rome, Italy; and ${ }^{\mathrm{c} C}$ ardiovascular Sciences Department, Agostino Gemelli Foundation Policlinic IRCSS, Catholic University of The Sacred Heart, Rome, Italy.

Disclosures: Authors have nothing to disclose with regard to commercial support.

Received for publication July 27, 2018; revisions received Aug 21, 2018; accepted for publication Aug 29, 2018; available ahead of print Oct 23, 2018.

Address for reprints: Giovanni A. Chiariello, MD, Cardiovascular Sciences Department, Agostino Gemelli Foundation Policlinic IRCSS, Rome, Italy, Largo A. Gemelli 8,00168 Rome, Italy (E-mail: gio.chiariello88@ tiscali.it). J Thorac Cardiovasc Surg 2019;157:e163-6 $0022-5223 / \$ 36.00$

Copyright (C) 2018 by The American Association for Thoracic Surgery https://doi.org/10.1016/j.jtcvs.2018.08.099
}

- Video clip is available online.

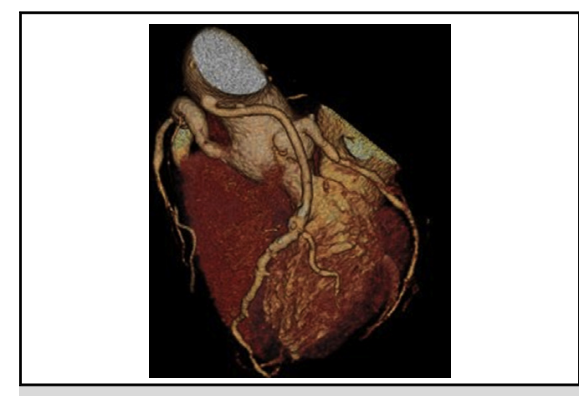

Postoperative CT scan reconstruction of the left main stem coronary artery.

Central Message

In left main stem reconstruction after removal of a giant aneurysm of the left main stem coronary artery, the aortocoronary continuity was restored by saphenous vein graft interposition.
We propose an original technique that we adopted in a patient with a giant aneurysm of the left main stem coronary artery (LMS), thus restoring the aortocoronary continuity.

\section{CLINICAL SUMMARY}

A 76-year-old old man with hypertension and obesity had first been admitted to our hospital in 2015 for subendocardial myocardial infarction and at that time was successfully treated with thrombolytic therapy. Coronary angiography had shown a $17 \times 27-\mathrm{mm}$ fusiform aneurysm localized in the distal tract of the LMS involving the origin of the left anterior descending coronary artery (LAD) and the circumflex artery $(\mathrm{Cx})$. The heart team opted for conservative medical therapy with antihypertensive drugs, acetylsalicylic acid and warfarin.

In February 2018 a new computed tomographic scan (Figure 1) showed an enlargement of the aneurysm, reaching diameters of $65 \times 45 \mathrm{~mm}$, with intraluminal 9- to $10-\mathrm{mm}$

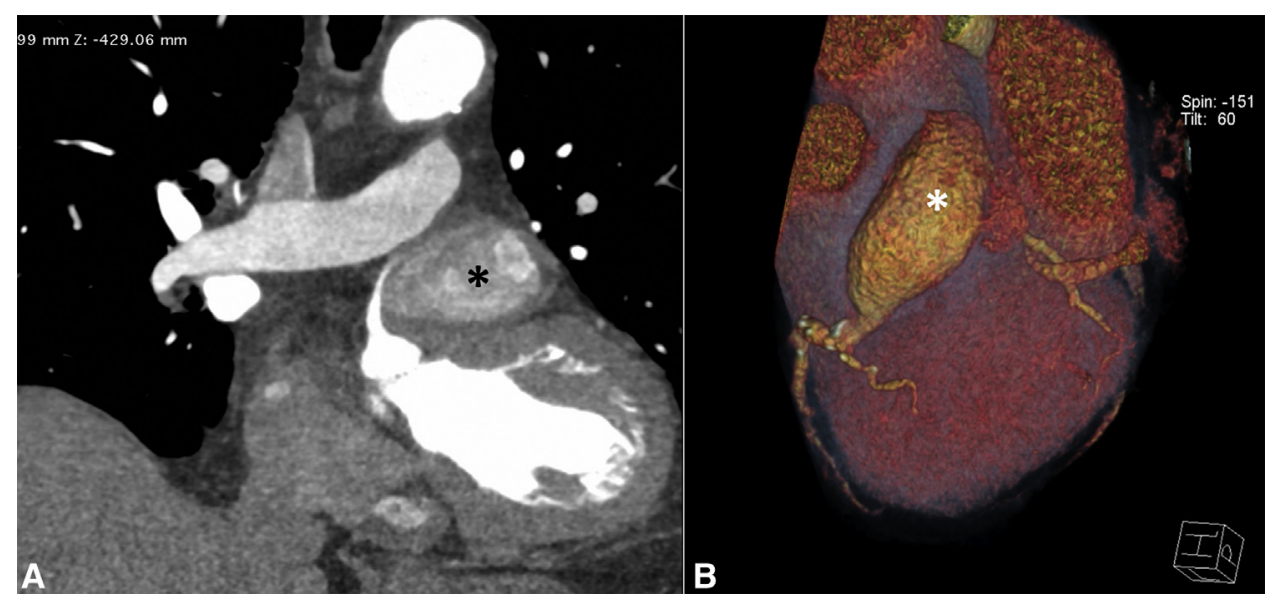

FIGURE 1. Angiographic computed tomographic scan in 2-dimensional coronal view (A) and in 3-dimensional reconstruction (B) showing the left main stem coronary artery aneurysm (asterisks). 


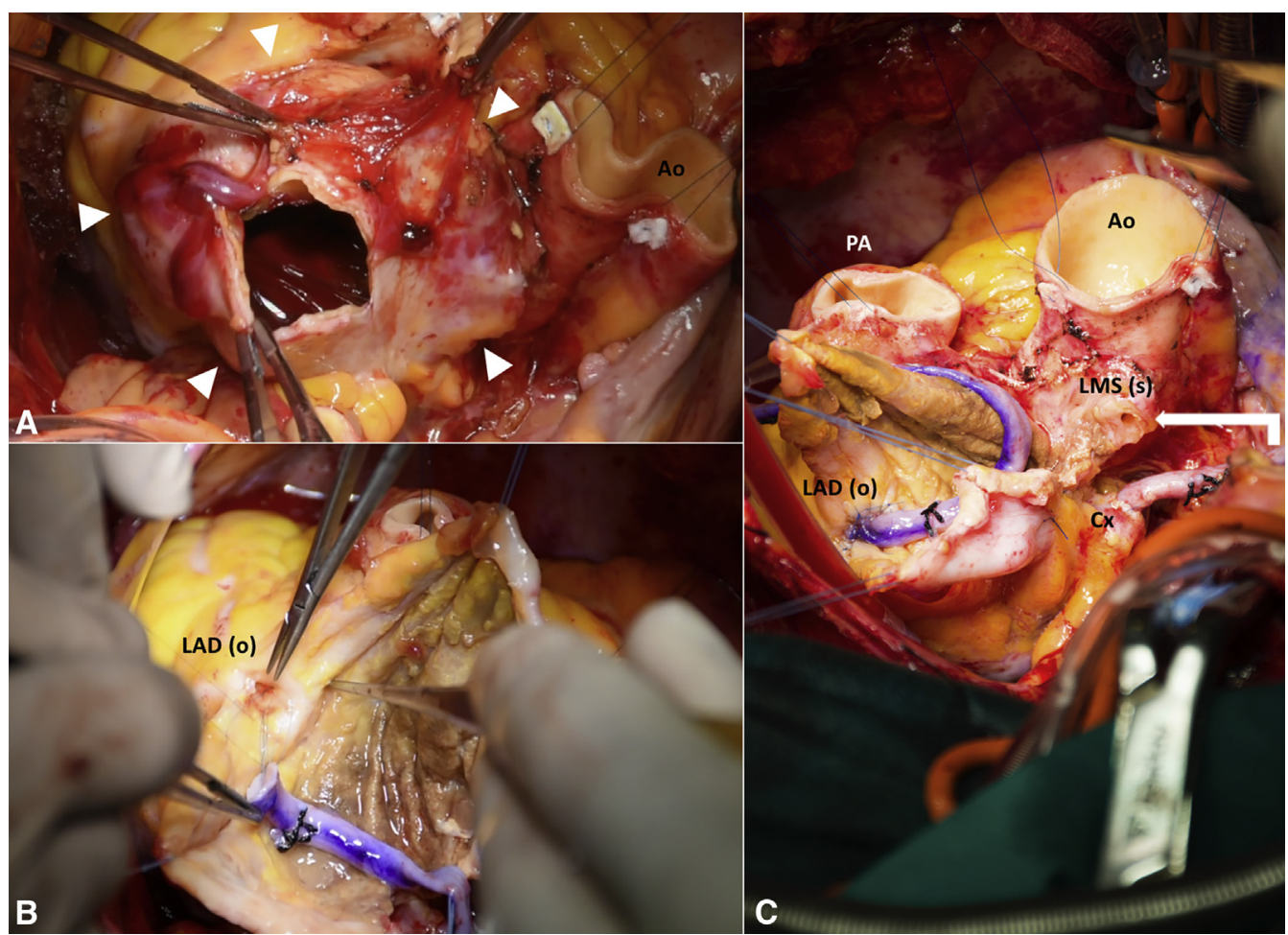

FIGURE 2. Operative view. A, Incision of the giant aneurysm (bordered by white triangles) and the detection of internal thrombotic fragments. B, End-toend anastomosis between the saphenous graft with the left anterior descending coronary artery ostium $(L A D(o))$. C, Both distal anastomoses on the left anterior descending coronary artery ostium $(L A D(o))$ and on the coronary artery $(C x)$. White arrow indicates the subsequent end-to-end anastomosis of the vein graft on the left main stem stump $(L M S(s))$. PA, Pulmonary artery; Ao, aorta.

thrombotic stratification. The LAD and Cx originated from the aneurysm and presented severely slow coronary flow. The proximal right coronary artery was ectasic $(25 \mathrm{~mm})$ and presented a $70 \%$ stenosis in its middle tract. Echocardiography showed normal left ventricular function (ejection fraction of $66 \%$ ). New heart team evaluation at this time indicated surgical correction.

The operation was performed through a median sternotomy under mild hypothermia $\left(33^{\circ} \mathrm{C}\right)$ with aortic and bicaval cannulation. At surgical inspection, the left internal thoracic artery was unexpectedly narrow and tortuous, with high risk of caliber discrepancy between the arterial graft and the coronary arteries. After aortic crossclamping, retrograde cold crystalloid cardioplegia was administered. To expose the aneurysm, the ascending aorta and the pulmonary artery trunk were completely transected. The aneurysm measured $70 \times 40 \mathrm{~mm}$. It involved the distal tract of the LMS and ended at the origin of the LAD and the Cx. The proximal tract $(1 \mathrm{~cm})$ of the LMS was normal. The aneurysm was entered through a longitudinal incision, and thrombotic material was removed. There were several atherosclerotic plaques disseminated in the aneurysmal wall. The coronary ostia were identified. The $\mathrm{Cx}$ ostium appeared to be occluded by a thrombotic plaque. The proximal $\mathrm{Cx}$ was isolated and transected. A first short saphenous vein coronary bypass was performed between the $\mathrm{Cx}$ and the proximal stump of the LMS, because of the short distance between them, with 2 end-to-end anastomoses. The LAD ostium was patent. After careful débridement, a second aortocoronary bypass was performed between the ascending aorta and the LAD by interposition of a longer saphenous graft end-to-end was distally sewn to the LAD ostium (Figure 2 and Video 1). The ascending aorta and the pulmonary artery were reconstructed with polypropylene running sutures. The proximal anastomosis on the ascending aorta of the

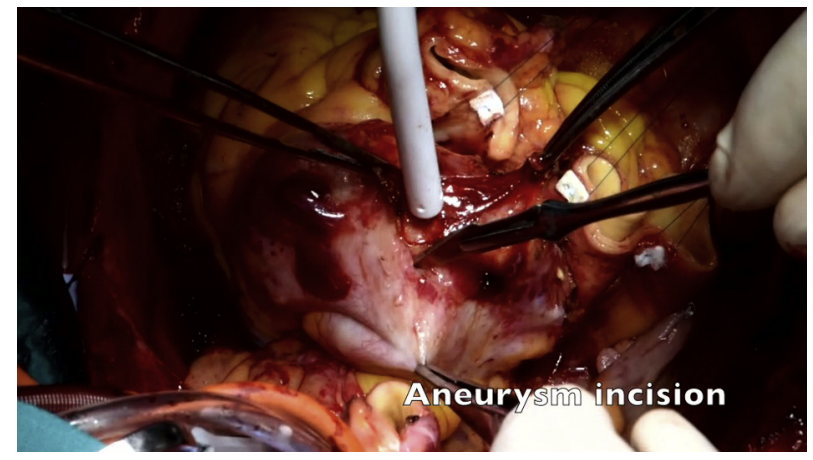

VIDEO 1. Surgical left main stem correction. $L A D$, Left anterior descending coronary artery; $C x$, circumflex coronary artery, $L M$, left main stem coronary artery; $R C A$, right coronary artery. Video available at: https://www. jtcvs.org/article/S0022-5223(18)32494-2/fulltext. 

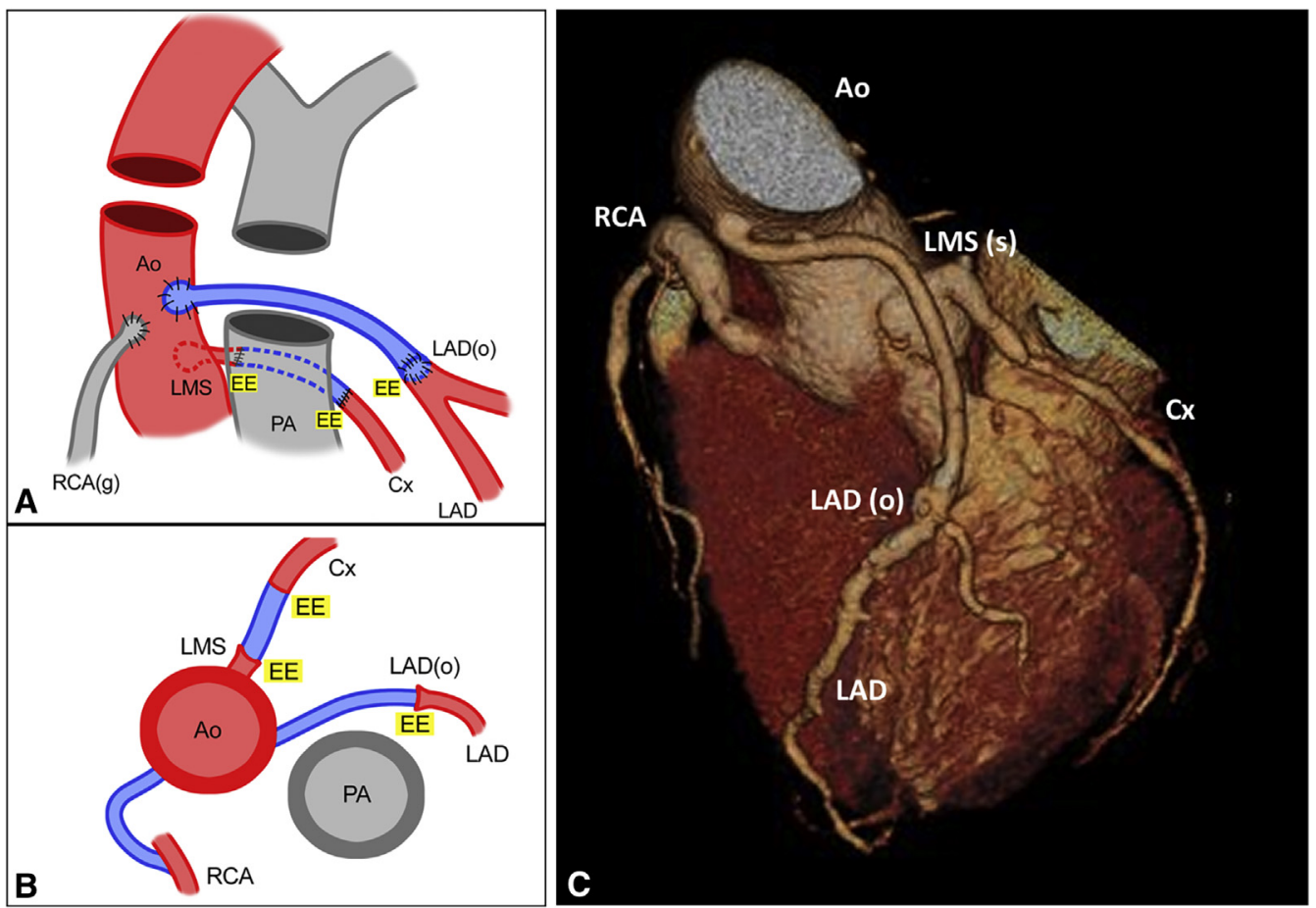

FIGURE 3. Drawings of the final result (A and B) and postoperative angiographic computed tomographic scan (C). Ao, Aorta, $L A D(o)$, ostium of the left anterior descending coronary artery; $L M S$, left main stem coronary artery; $E E$, end-to-end anastomosis; $P A$, pulmonary artery; $R C A(g)$, right coronary artery graft; $C x$, circumflex coronary artery; $L A D$, left anterior descending coronary artery; $R C A$, right coronary artery; $L M S$ ( $s$ ), stump of the left main stem coronary artery.

saphenous vein for the LAD ostium was performed. The procedure was completed with the right saphenous vein aortocoronary bypass. Cardiopulmonary bypass time was 239 minutes, and aortic crossclamp time was 160 minutes. Weaning from cardiopulmonary bypass was regular, with no evidence of myocardial ischemia. The postoperative course was uneventful. Postoperative computed tomographic scan confirmed complete exclusion of the coronary aneurysm and optimally reconstructed coronary arteries (Figure 3).

The institutional review board approved the report of this case.

\section{DISCUSSION}

Giant $(>20 \mathrm{~mm})$ isolated aneurysms of the LMS are uncommon and usually asymptomatic until development of myocardial ischemia. Indication for treatment depends on possible complications, such as obstructive thrombosis or embolization to the peripheral coronary branches, coronary dissection, rupture, or wall erosion penetrating into surrounding structures. ${ }^{1,2}$ The natural history of coronary aneurysms is uncertain. Because of their rarity, it is difficult to establish guidelines to define the appropriate treatment. Accordingly, small asymptomatic aneurysms could be simply observed at the follow-up, whereas patients with giant aneurysms that are either progressively enlarging or causing symptoms of angina should be managed surgically. Traditionally, LMS aneurysms are treated by simple aneurysmal exclusion, ligating afferent and efferent vessels and restoring blood flow with multiple coronary artery bypass grafting. ${ }^{1,2}$

Occasionally, other alternative surgical options have been proposed. Lepojärvi and colleagues ${ }^{3}$ and Anderson and associates ${ }^{4}$ proposed the successful LMS reconstruction by interposition of an autogenous Y-shaped bifurcated arterial graft (hypogastric artery and lateral circumflex femoral artery, respectively). Furthermore, in the second case 2 aortocoronary bypasses were implanted as a precautionary measure in case of early spasm or distortion of the arterial graft. Matsubayashi and colleagues ${ }^{5}$ reported a case of LMS distal aneurysm exclusion with an ascending aorta-LAD bypass with interposition of a small tubular Dacron polyester fabric graft. An initial attempt to suture the proximal LAD directly to the ascending aorta caused pulmonary artery compression and impaired weaning from cardiopulmonary bypass.

Aneurysm ligation and multiple distal aortocoronary bypass may be time-consuming and may not allow complete revascularization. We propose the reconstruction of the left main stem coronary artery by saphenous vein graft interposition. With only 3 coronary bypasses, we obtained 
complete revascularization of the left ventricle in a patient without distal left coronary stenoses. In addition, end-toend anastomoses avoids blood flow stasis and possible thrombosis in the upstream cul-de-sac typical of end-toside anastomoses.

In this challenging scenario, interposition of an easily harvestable autogenous saphenous vein avoids prosthetic materials and provides adequate blood flow without risk of graft distortion, compression, and vasospasm, thus preventing early myocardial ischemia.

\section{References}

1. Li D, Wu Q, Sun L, Song Y, Wang W, Pan S, et al. Surgical treatment of giant coronary artery aneurysm. J Thorac Cardiovasc Surg. 2005;130:817-21.

2. Tuncer E, Onsel Turk U, Alioglu E. Giant saccular aneurysm of the left main coronary artery. J Geriatr Cardiol. 2013;10:110-2.

3. Lepojärvi M, Salmela E, Huikuri H, Kärkölä P. Repair of an aneurysm of the left main coronary artery. Ann Thorac Surg. 1996;61:1247-9.

4. Anderson CA, Filsoufi F, Kadner A, Adams DH. Repair of a left main coronary artery aneurysm using the circumflex femoral artery as a Y-interposition graft. Ann Thorac Surg. 2004:78:314-6.

5. Matsubayashi K, Asai T, Nishimura O, Kinoshita T, Ikegami H, Kambara A, et al. Giant coronary artery aneurysm in the left main coronary artery: a novel surgical procedure. Ann Thorac Surg. 2008;85:2130-2. 